\title{
THERMOGRAVIMETRIC ANALYSIS AS SIGNIFICANT TOOL FOR SUITABILITY ASSESSMENT OF SOLID WASTE DESTINED FOR PROCESSING BY THERMAL DESORPTION
}

\author{
HENDRYCH J. ${ }^{1}, *$ \\ KUBAL M. ${ }^{1}$, \\ EDEROVÁ J. ${ }^{2}$, \\ MAŠíN P. ${ }^{1}$
}

\author{
${ }^{1}$ Department of Environmental Chemistry \\ Institute of Chemical Technology, Prague, Czech Republic \\ ${ }^{2}$ Central Laboratories \\ Institute of Chemical Technology, Prague, Czech Republic
}

*to whom all correspondence should be addressed: e-mail: Jiri.Hendrych@vscht.cz

\section{ABSTRACT}

Thermogravimetric analysis combined with a mass spectroscopy detector was used to study the thermal stability of solid materials earmarked for processing by thermal desorption (for example during the amelioration of environmental damage). The objective of the study was to verify the applicability of thermogravimetric analysis as a simple and fast tool capable of providing basic information about the behavior of a particular solid material during its heating to a given temperature. Samples of materials representing the spectrum of solids customarily treated during environmental remediation (soils, bricks, and concrete) were used as the model solid matrices. The measurements demonstrated a high informative power of thermogravimetric analysis, which may help predict many technologically important aspects of the thermal desorption process.

Keywords: thermogravimetry, decontamination process, thermal desorption

\section{Introduction}

Thermal desorption is nowadays routinely used in decontaminations of solid materials. The method involves heating the contaminated material to higher temperatures at which the (originally immobile) contaminants are released as gases or vapors. Thermal desorption equipment in common use can be classified according to several criteria. For one, it can be classified by temperature-low temperature equipment (up to circa $320^{\circ} \mathrm{C}$ ) and high temperature equipment (up to circa $560{ }^{\circ} \mathrm{C}$ ). It can also be classified by heating source- direct or indirect. A typical thermal desorption equipment includes a unit for mechanical pretreatment of the contaminated material, the thermal desorber itself (most often a directly or indirectly fired rotary dryer), and a unit for handling of the resulting vapors, gases and condensates. The primary outputs from a thermal desorption equipment are the decontaminated solid matrix and the contaminant usually concentrated as a condensate that must be further processed.

In environmental remediation, thermal desorption is suitable for the decontamination of a wide range of polluted solid materials such as soils and building materials containing polyaromatic hydrocarbons, polychlorinated contaminants, non-volatile petroleum derivates (US EPA 2001, Technical Report 1998) and mercury (Matějü, 2006). Therefore, this remediation method is applicable on the premises of abandoned coke plants, refineries, gasworks, chemical plants and warehouses. Among the known 
remediation projects based on the method of thermal desorption belong the rehabilitation of a locality polluted in the course of manufacturing and handling of pesticides (Georgia) (US EPA 2005), the decontamination of a plant manufacturing adhesives and rubber (New Jersey) (US EPA 2003), a rehabilitated area polluted during the manufacturing of pesticides (Tennessee) (US EPA 2000), the decontamination of an abandoned coke plant Karolina in Ostrava (Czech Republic) (Cizkova et al., 1998), and the decontamination of pollution with dioxins in Spolana, Neratovice (Czech Republic) (Přibyl et al. 2007; Bozek et al. 2010).

Technical equipment used in thermal desorptions is relatively challenging in terms of both its construction and its operation. The demands on construction generally come from the legislative requirements of very high effectiveness in the removal of contaminants from the solid matrix, from the necessity of purifying the contaminated water, technological off-gas and the concentrated contaminants, and from the need to protect the working environment and the surroundings against dust and gas emissions. The demands on equipment operation are connected with the often erratic composition of the input material that must not affect the quality of the decontaminated product. The fluctuating composition of the input material sometimes leads to a change in the important operating parameters in the range of several orders and makes operating the thermal desorption equipment a difficult task. It is therefore advantageous to determine the composition of the contaminated material ahead of time to avoid possible operating complications (Kubal and Hendrych, 2009). The thermogravimetric analysis is one of the tools that can be used to this end.

Thermogravimetric analysis found wide use in the study of the processes taking place in thermally stressed materials. It is used to evaluate material stability, to monitor the conditions under which certain phenomena occur, to define the kinetic parameters of the processes, and to determine the effects of additives on the properties of the materials. Thermogravimetric analysis has found applications in many specific disciplines, ranging across the fields of food chemistry (Šárka et al., 2009; Rey et al., 1988), polymer chemistry (Pommerenke, 2008), characterization of the properties of explosives (Hentze and Krien, 1986), biochemistry (Olafsson and Bryan, 1970; Rodríguez-Méndez et al. 1988), mineralogy (Emmerich and Smykatz-Kloss, 2002; Mielenz et al., 1953) and others. The method is a good tool for the evaluation of decontamination processes that involve heating of contaminated solid materials (Kubal and Hendrych, 2009). The method has the advantages of being uncomplicated, requiring short times, and providing a wealth of information about many criteria that are used to describe the properties of solid materials. Thermogravimetric analysis requires a very small amount of the measured material in a sample. Special care is necessary during sampling and during sample pretreatment when taking samples from notoriously non-homogeneous contaminated materials.

The principle of thermographic analysis (TGA) (Gallagher, 1998; Kealey and Haines, 2002) lies in the determination of the mass of a sample in the course of its heating on a high precision thermobalance. Modern thermobalances utilize electromagnetic compensation. The measurements may take place at a constant temperature but in most cases a dynamic process, in which the crucible with the sample is continuously heated, is employed. Different temperature programs are available, though most often a linear temperature change with time is used. Air or an inert gas may flow past the sample during the measurement. When using this arrangement, it is advantageous to approximate the conditions of the process to which the results of measurement will be applied. In differential thermal analysis (DTA) (Kealey and Haines, 2002; Bud and Warner, 1998), a sample of the material under the study and an inert reference material are heated together at the same rate. The temperature difference between the sample and the reference material, caused by physical and chemical changes within the sample, is then recorded. The temperature difference between the sample and the reference material reveals information about the heat effects of the processes taking place in the sample. Mass spectroscopy (MS) can supply additional data based on the analysis of the products being formed during the heating of the sample. These products are transported within the stream of the carrier gas that flows past the heated crucible in which the sample resides. The spectrometric data aid in the identification of the processes taking place within the sample or can be used to refine the information about the processes. 


\section{Experimental}

Samples of concrete, bricks, and soil representing the spectrum of materials commonly treated with the help of ex-situ thermal processes in the course of environmental remediation were used in the experiments. The samples were first dried at laboratory temperature for the duration of five days and then were homogenized with the help of a swing-hammer pulverizer to a particle size off less than $0.1 \mathrm{~mm}$. This was followed by further drying for a duration of three days.

The method employs a number of different measuring elements, whose utilization is more or less optional. The choice of elements depends on the objectives of the analysis. A conventional configuration of the elements, which provided the results of the thermogravimetric analysis that was used in our experiments is depicted in Fig. 1. The curve of mass loss during the heating was constructed on the basis of the measurement of the mass decrement $(\Delta \mathrm{m})$. The curve of heat change of the ongoing processes was constructed on the basis of the measurement of the temperature difference between the reference crucible and the crucible containing the specimen $(\Delta \mathrm{T})$. Productions of $\mathrm{CO}_{2}$ and $\mathrm{H}_{2} \mathrm{O}$ during the process were determined with the help of a mass spectrometer.

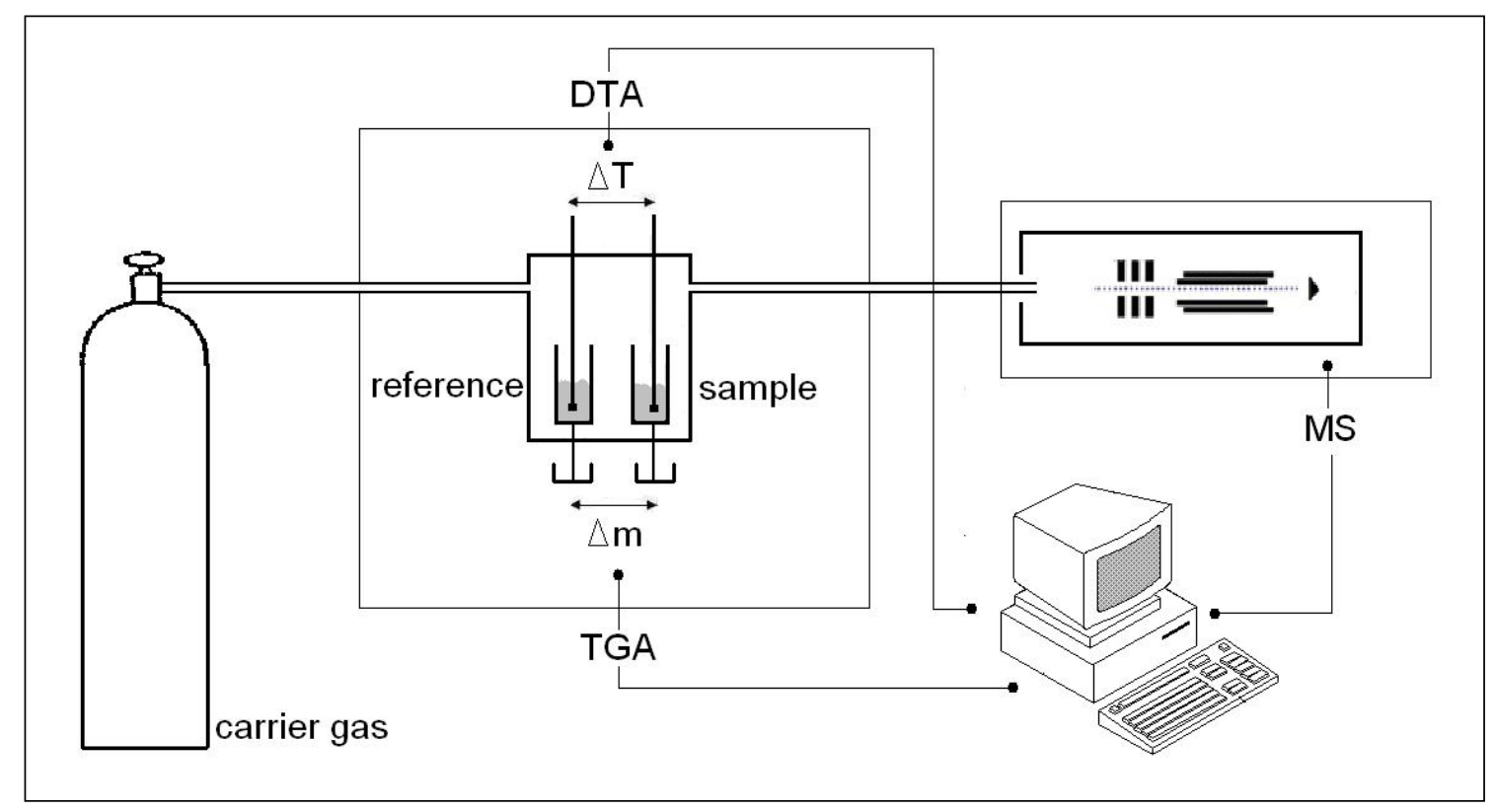

Figure 1. Schema of the analysis employing TGA,DTA, and MS

The model Setsys Evolution, manufactured by Setaram, was used to perform thermogravimetric analysis (TGA) and differential thermal analysis (DTA) simultaneously. The apparatus was complemented by a mass spectrometer (MS) made by Pfeiffer Vacuum, model OmniStarTM, used to detect gaseous substances released during the thermal analysis. This mass spectrometer is of a quadruple type, with the mass range from 1 to $300 \mathrm{amu}$. The weight of the sample for the thermogravimetric analysis was approximately $50 \mathrm{mg}$, and the heating rate was $10 \mathrm{oC} / \mathrm{min}$ in a stream of a technical air taken from a cylinder. The temperature range was $25-1000^{\circ} \mathrm{C}$.

\section{Results and Discussion}

The selected configuration of measuring elements provided a graphical representation of the dependency of five values (temperature, mass loss, heat flux, the amount of water vapor produced, and the amount of carbon dioxide produced).on time, respectively (provided temperature has changed linearly with time) the dependency of four values (mass loss, heat flux, the amount of water vapor produced, and the amount of carbon dioxide produced) on temperature. 
Often the mass loss of the sample is difficult to record and impossible to evaluate visually. Better visualization of the mass loss dependency on the increasing temperature is accomplished by using the derivative of this function as shown in Fig.2. The bold curve depicts the mass loss as a function of temperature; the thin curve depicts the reciprocal values of the derivative of this function. Local maxima on the thin curve correspond to the temperatures at which the sample undergoes specific processes (drying, decomposition, oxidation etc.). The derivative of the mass loss function is especially useful in situations where there is no additional information (such as data from differential thermal analysis or mass spectroscopy) available.

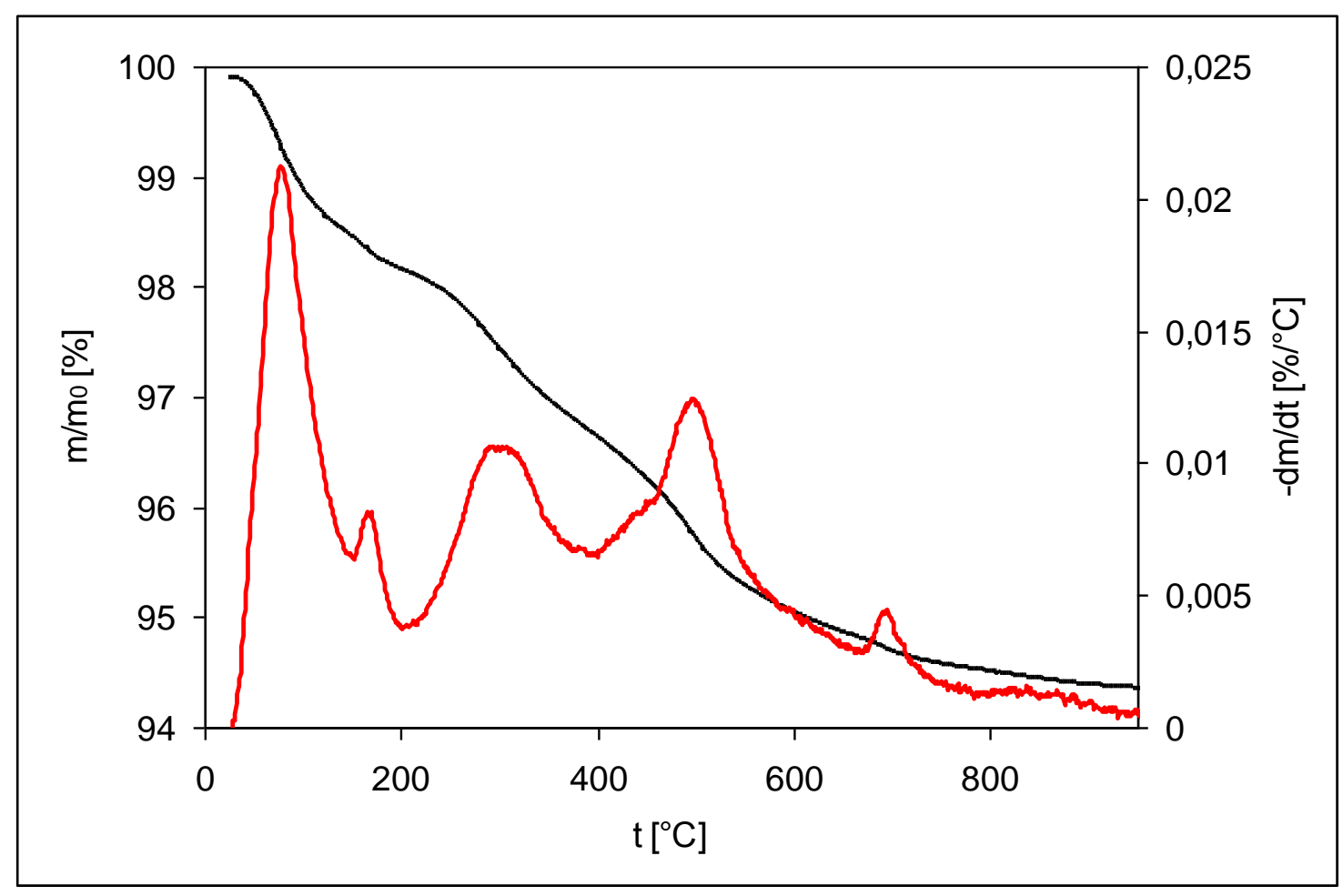

Figure 2. The thermogravimetric curve depicting the mass loss of a sample of soil (Z) during its heating and the reciprocal values of the derivative of the curve

The actual interpretation of the curves is explained for the following figures (Fig.3a-Fig.3d.) The figures show successively the samples' mass changes with temperature, the heat effects of the processes taking place, and the response of the mass detector to the molecules of water and carbon dioxide carried out by the carrier gas in the course of the controlled heating. Each figure depicts data measured on samples of concrete (B), bricks (C), and soil (Z). Only the mass loss can be quantified. The heat effects and the function of water and carbon dioxide release have only qualitative character. They aid in the correct interpretation of the processes taking place. The curves are self-explanatory. Only with respect to the function of the heat flux on the temperature it is necessary to explain that a local minimum represents an endothermic process, and a local maximum represents an exothermic process.

The examined samples were selected in such a way that it was possible to identify the most frequent processes taking place in the majority of the samples. Concrete (B) and bricks (C) represent typical construction waste well suited for eventual thermal decontamination.

Soil (Z) was chosen for its content of naturally occurring organic humic-like components. 


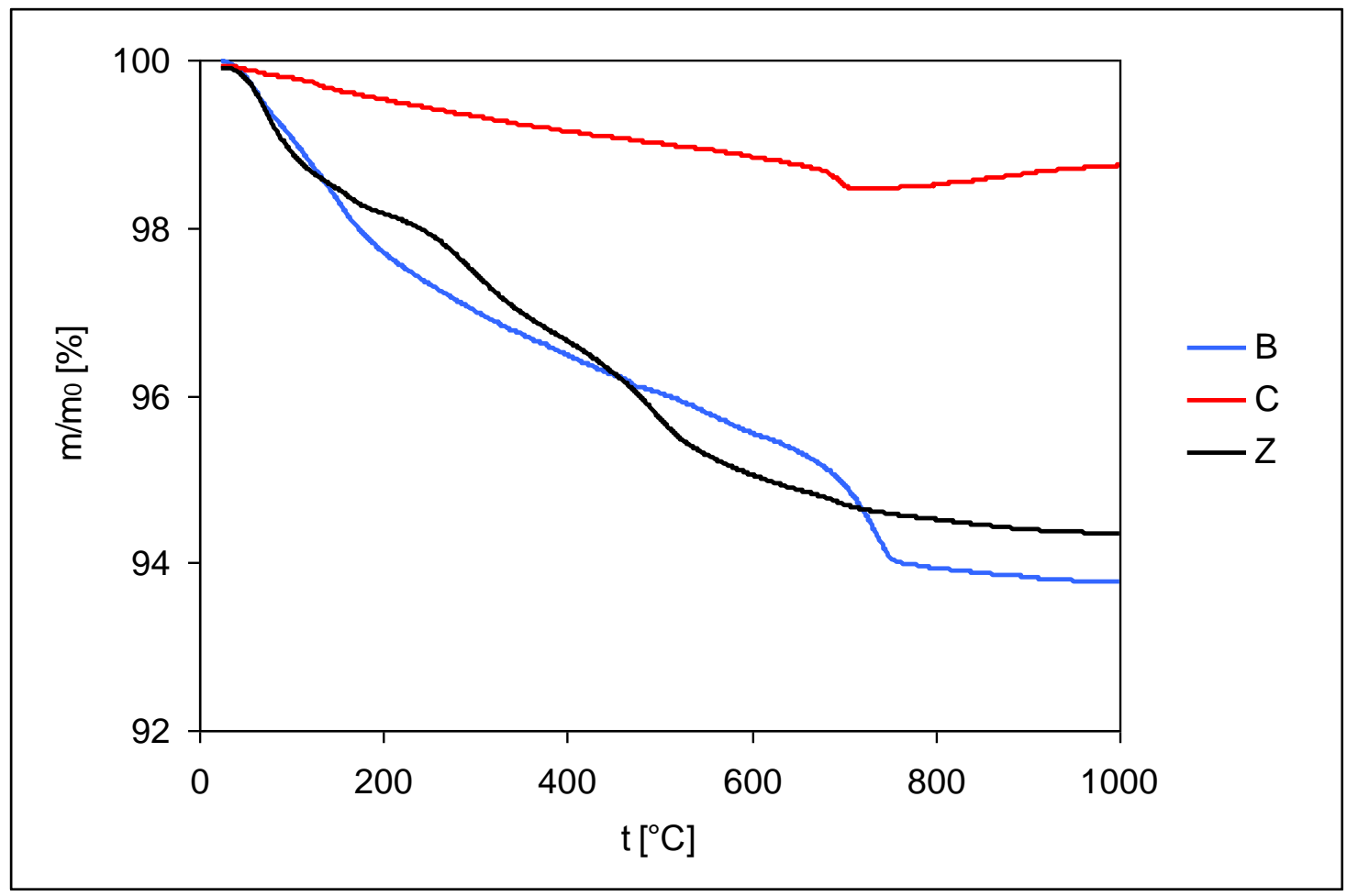

Figure 3a. Mass loss as a function of temperature

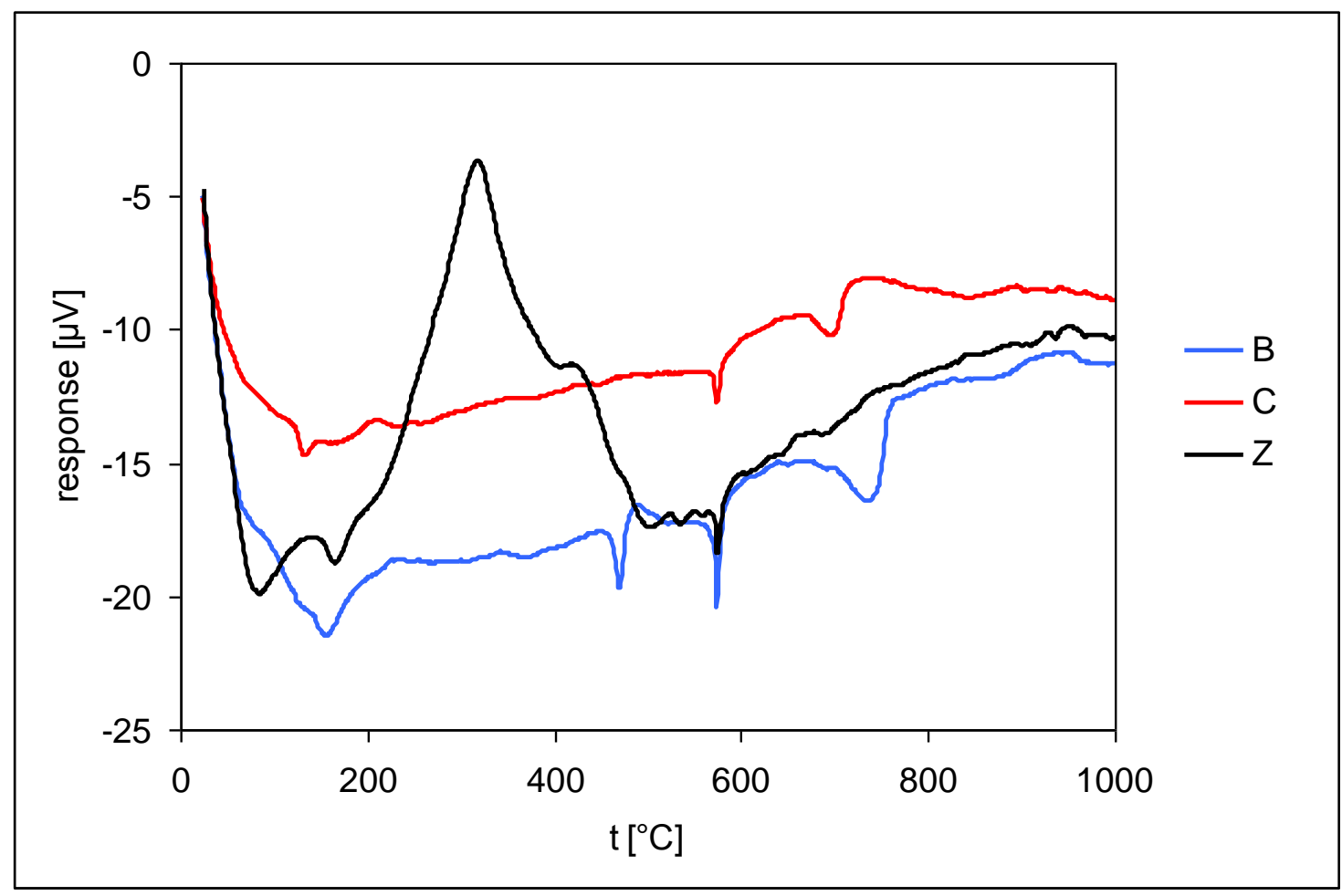

Figure $\mathbf{3 b}$. Heat flux as a function of temperature 


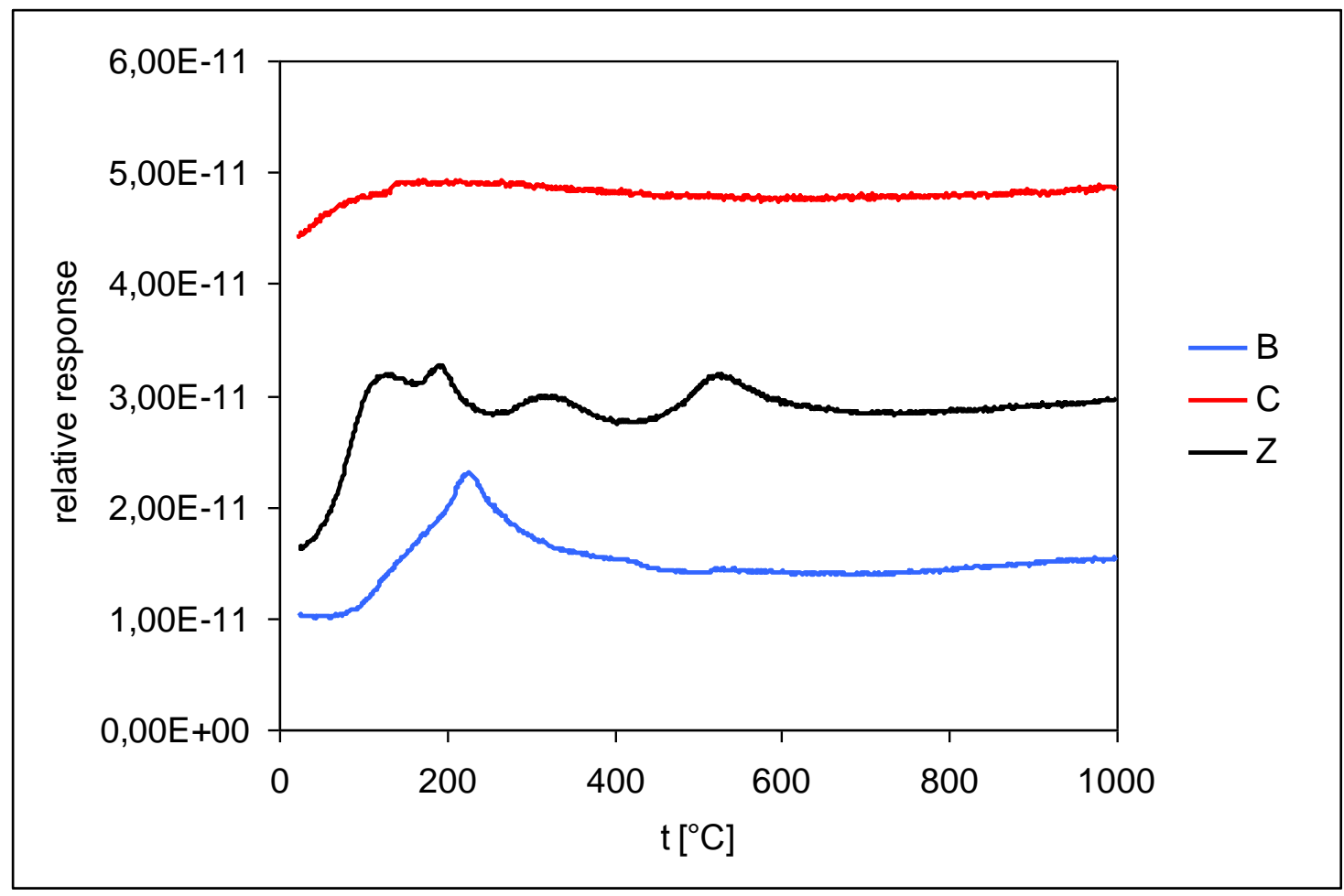

Figure 3c. Detection of $\mathrm{H}_{2} \mathrm{O}$ by $\mathrm{MS}$ as a function of temperature

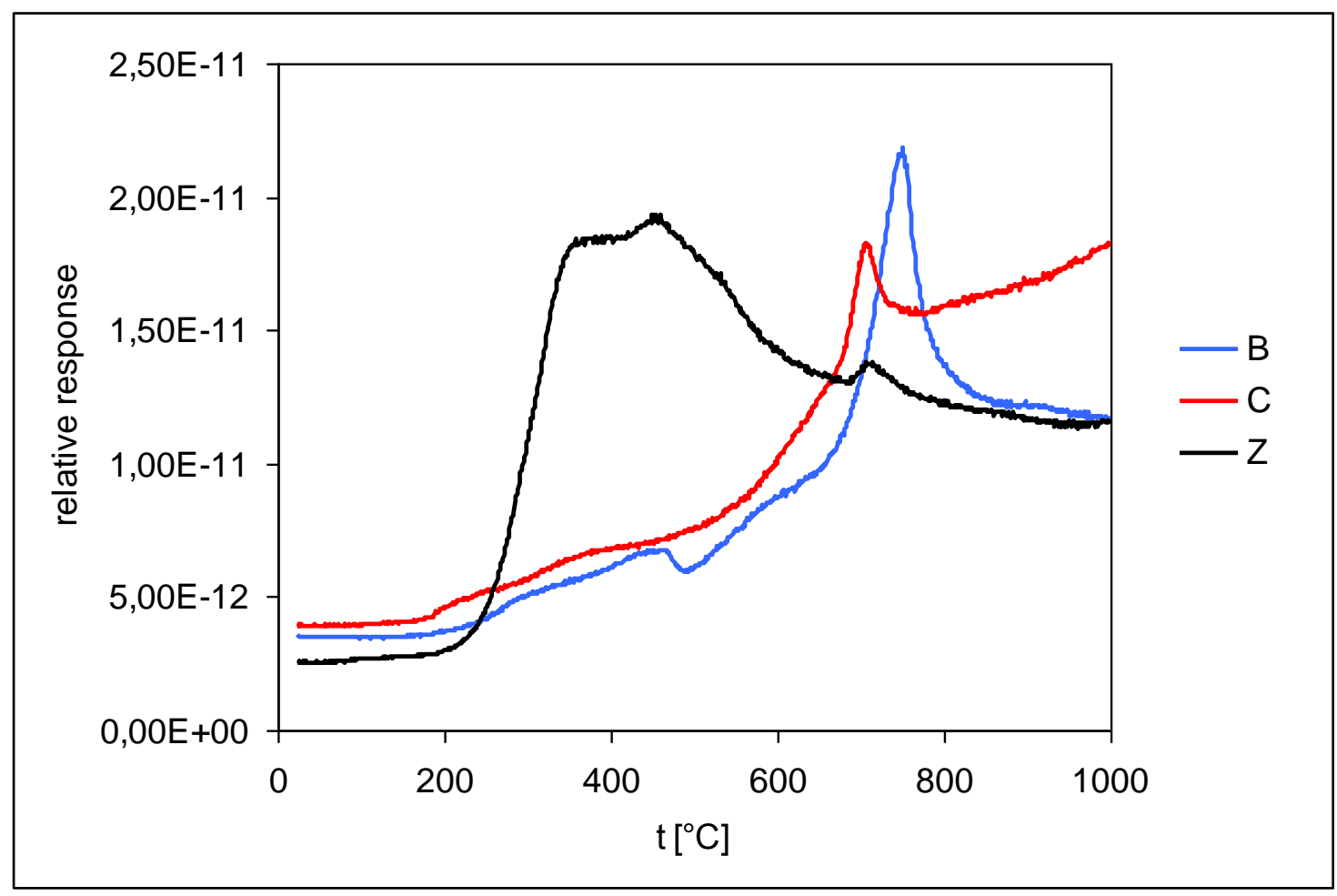

Figure 3d. Detection of $\mathrm{CO}_{2}$ by $\mathrm{MS}$ as a function of temperature

A more detailed description of the processes that occur while the temperature increases follows: At temperatures below $100{ }^{\circ} \mathrm{C}$, drying takes place, with the most vigorous evolution of the vapor happening around the water boiling point. Next, both water bound in hydrates and interstitial water of the crystalline structures is eased off. The individual forms of water within the sample manifest 
themselves as local maxima on the curve of the mass detector's response to water. As seen on the heat flux curve, these events are endothermic. At temperatures above $220^{\circ} \mathrm{C}$, destruction of organic material (Buurman et al. 2002) takes place. Besides the exothermic reaction, the evolution of the oxidation products-carbon dioxide and water-evidence the destruction. Local maxima occur on the mass detector curve according to the particular type of the organic matter being destroyed. The organic substances that are more resistant to the oxidation, degrade at higher temperatures. Their decomposition is completed around $500{ }^{\circ} \mathrm{C}$. The endothermic process taking place at $573{ }^{\circ} \mathrm{C}$, (Haynes, 2014; Lønvik and Smykatz-Kloss 1984) unaccompanied by the evolution of carbon dioxide, is characteristic of the transformation of the crystalline modifications of silicon dioxide, which was present in significant quantities in the examined samples. As the heating continues above $650{ }^{\circ} \mathrm{C}$, destruction of the carbonates (Maitra et al., 2008) takes place. The corresponding graphs show endothermic reactions and evolution of carbon dioxide. The eventual increase in the mass of the sample at high temperatures is caused by the oxidation of the samples' matrix, and comes out as an endothermic process.

\section{Conclusion}

In many cases, interpretation of thermogravimetric analysis data is difficult. However, the contribution of this method to the process of evaluation of decontamination applications that are based on heating of solid materials is clear, and this type of analysis should not be left out. For example, during the initial assessment of the applicability of thermal desorption for a given decontamination, thermogravimetric analysis allows for quick and relatively inexpensive determination of the behavior of the solid matrix at the proposed temperatures. Information about the properties of the matrix material itself is as important as information about the contaminants. Information on the amount of produced vapor is important for the assessment of the condensers' loads. The content of organic material in the matrix determines the amount of gaseous decomposition products and the increase in the gas removal equipment loads. Information about the stability of the decontaminated material is crucial in case the material should be recycled. These are all properties of the solid material that must be taken into the consideration when determining the suitability or elimination of a decontamination method that is based on heating the material to temperatures on the order of hundreds degrees of Celsius.

\section{Acknowledgement}

The study was a part of the research supported by the project: Investigation of thermal desorption technology for the removal of persistent organic substances from solid contaminated matrices (SP/2f3/133/08).

\section{References}

Bozek F., Komar A., Dvorak J. and Obermajer J. (2010), Implementation of best available techniques in the sanitation of relict burdens, Clean Technol. Envir, 12, 9-18.

Bud R. and Warner D.J. (1998), Instruments of Science, Garland Publishing, New York/London.

Buurman P., Van Lagen B. and Piccolo A. (2002), Increase in stability against thermal oxidation of soil humic substances as a result of self association, Org. Geochem, 33, 367-381.

Cizkova H., Zenaty L., Tylcer J. and Grmela A. (1998), Management of the remediation and re-use of contaminated industrial sites in the Czech Republic- Karolina site, Ostrava. In: Proceedings of the Groundwater Quality: Remediation and Protection Conference, September 1998, Tübingen, Germany, 35-40.

Emmerich K. and Smykatz-Kloss W. (2002), Exothermic effects in soils during thermal analysis, Clay. Miner., 37, 575-582.

Gallagher P.K. (1998), Handbook of Thermal Analysis and Calorimetry, Elsevier Science B. V., Amsterdam.

Handbook of Chemistry and Physics, Section 4 - Physical Constants of Inorganic Compounds, Available from http://www.hbcpnetbase.com/. (Accessed September 14, 2009).

Hentze G. and Krien G. (1986), Über DTA-untersuchungen von explosivstoffen im einschluß. Thermochim. Acta, 107, 61-74.

Kealey D. and Haines P.J. (2002), Analytical Chemistry, BIOS Scientific Publishers Ltd., Oxford. 
Kubal M. and Hendrych J. (2009), Thermal desorption of polychlorinated substances from solid waste and soil, Odpadové forum, 10, 26-27.

Lønvik K. and Smykatz-Kloss W. (1984), Comparative studies of structural transformations of carbonate and silica minerals by means of thermosonimetry and differential thermal analysis, Thermochim. Acta, 72, 159-163.

Maitra S., Chakrabarty N. and Pramanik J. (2008), Decomposition kinetics of alkaline earth carbonates by integral approximation method, Ceramica, 54, 268-272.

Matějů V. (2006), Kompendium sanačních technologií, Vodní zdroje Ekomonitor s.r.o., Chrudim.

Mielenz R.C., Schieltz N.C. and King M.E. (1953), Thermogravimetric Analysis of Clay and Clay-Like Minerals, Clay Clay. Miner., 2, 285-314.

Olafsson P.G. and Bryan A.M. (1970), Evaluation of Thermal Decomposition Temperatures of Amino acids by Differential Enthalpic Analysis, Microchim. Acta, 58, 871-878.

Pommerenke K. (2008), Quality Assurance of Polymers by Thermal Analysis, CHEMagazín, 18, 22-23.

Přibyl R., Kubal M. and Hamilton G. (2007), Sequential Thermodesorption and Non-Combustion Decomposition Technologies Destroy Dioxins and Pesticide Waste, US EPA Technology News and Trends, 28, 1-2.

Rey F.J., Ramos-Sánchez M.C., Rodríguez M.L., Martín-Gil J. and Martín-Gil F.J. (1988), DTG and DTA Studies on Sugar Derivatives, Thermochim. Acta, 134, 67-72.

Rodríguez Méndez M.L., Rey F.J., Martín-Gil J. and Martín-Gil F.J. (1988), DTG and DTA Studies on Amino acids, Thermochim. Acta, 134, 73-78.

Šárka E., Ederová J. and Bubník Z. (2009), Thermogravimetry of Calcium Carbonate Determination in Sugar Technology Materials, Listy cukrov. repar., 125, 230-231.

Technical Report (1998), TR-2090-ENV, Naval Facilities Engineering Service Center, Port Hueneme, California.

U.S. Environmental protection agency (2000), Cost and Performance Summary Report Thermal Desorption at the Arlington Blending and Packaging Superfund Site Arlington, Tennessee, id. no. TND980468557.

U.S. Environmental protection agency (2001), A Citizenś Guide to Thermal Desorption, id. no. EPA 542-F-01-003.

U.S. Environmental protection agency (2003), Cost and Performance Summary Report Thermal Desorption at Industrial Latex Superfund Site, Wallington, New Jersey, id. no. NJD981178411.

U.S. Environmental protection agency (2005), Cost and Performance Summary Report Thermal Desorption at the T.H. Agriculture and Nutrition Site, OU2, Albany, id. no. GAD042101261. 